\title{
Melorheostosis associated with peripheral form spondyloarthropathy: new image with 18-fluoride positron emission tomoscintigraphy coupled to computed tomography
}

Open Access Rheumatology: Research and Reviews

5 January 2012

Number of times this article has been viewed

\author{
Hakim Hassani ${ }^{1-3}$ \\ Jérôme Slama ${ }^{1,3}$ \\ Gilles Hayem ${ }^{4}$ \\ Khadija Ben Ali ${ }^{1}$ \\ Laure Sarda-Mantel ${ }^{1,3}$ \\ Samuel Burgl,3 \\ Dominique Le Guludec ${ }^{1,3}$ \\ 'Department of Nuclear Medicine, \\ Hôpital Bichat, Paris, France; \\ ${ }^{2}$ Radiology, Hôpital Robert Debré, \\ Paris, France; ${ }^{3}$ University Paris \\ VII Denis Diderot, Paris, France; \\ ${ }^{4}$ Rheumatology, Hôpital Bichat, Paris, \\ France
}

\begin{abstract}
Melorheostosis is a rare benign bone pathology which can be responsible for incapacitating pain and bone deformations. Its imaging abnormalities are often typical. We describe here the case of a patient with melorheostosis involving the lower limbs, associated with a peripheral form of inflammatory spondyloarthropathy, who underwent ${ }^{18} \mathrm{FNa}$ positron emission tomography coupled to a computed tomography scan. Our objective is to present this new image, to show the value of this new modality and emphasize its advantages compared to the ${ }^{99 m}$ Technetium bone scan.
\end{abstract}

Keywords: melorheostosis, PET-CT, ${ }^{18} \mathrm{FNa}$, bone scan, ${ }^{18} \mathrm{~F}$-fluoride

\section{Introduction}

Melorheostosis is a rare bone disease easy to identify on plain radiographies. The extent of the disease is usually studied using a whole-body ${ }^{99 \mathrm{~m}} \mathrm{Tc}$-diphosphonates bone scan. We report here the case of a patient with a suspected associated diagnosis of peripheral form inflammatory spondyloarthropathy, who underwent an ${ }^{18} \mathrm{FNa}$ positron emission tomography (PET) coupled with computed tomography (CT). This new modality of whole-body imaging is based on an old, excellent bone radionuclide agent, in which interest is rising with the spread of PET-CT machines, and which will certainly become a very interesting tool for bone scanning in the near future. To the best of our knowledge, this is a new image in the medical literature.

\section{Case report}

The patient was a 36-year-old man with no significant previous disease except a gastric ulcer. He suffered from chronic right foot heel pain. He underwent radiographs that showed a cortical hyperostosis involving almost the entire right femur, the right tibia and the right foot (Figure 1A-E). These results were considered as typical of melorheostosis.

A ${ }^{99 \mathrm{~m}}$ Tc-diphosphonates bone scan ([HMDP bone scan] Infinia ${ }^{\mathrm{TM}}$ Hawkeye $^{\circledR}$; General Electric Healthcare, Chalfont St. Giles, UK) was performed to study the extent of the disease and showed an extensive increased uptake of nuclides consistent with the radiographic abnormalities on the right limb, and revealed a similar uptake in the left femur and tibia. The pubis bones were also both involved (Figure 2).
Correspondence: Hakim Hassan Department of Nuclear Medicine, Hôpital Bichat, 46 Rue Henri Huchard, 75018 Paris, France

Tel +33 |40256094

$\mathrm{Fax}+33955010778$

Email hassani.hakim@gmail.com
Open Access Rheumatology: Research and Reviews 2012:4 I-7

(C) 2012 Hassani et al, publisher and licensee Dove Medical Press Ltd. This is an Open Access article which permits unrestricted noncommercial use, provided the original work is properly cited.
Dovepress 

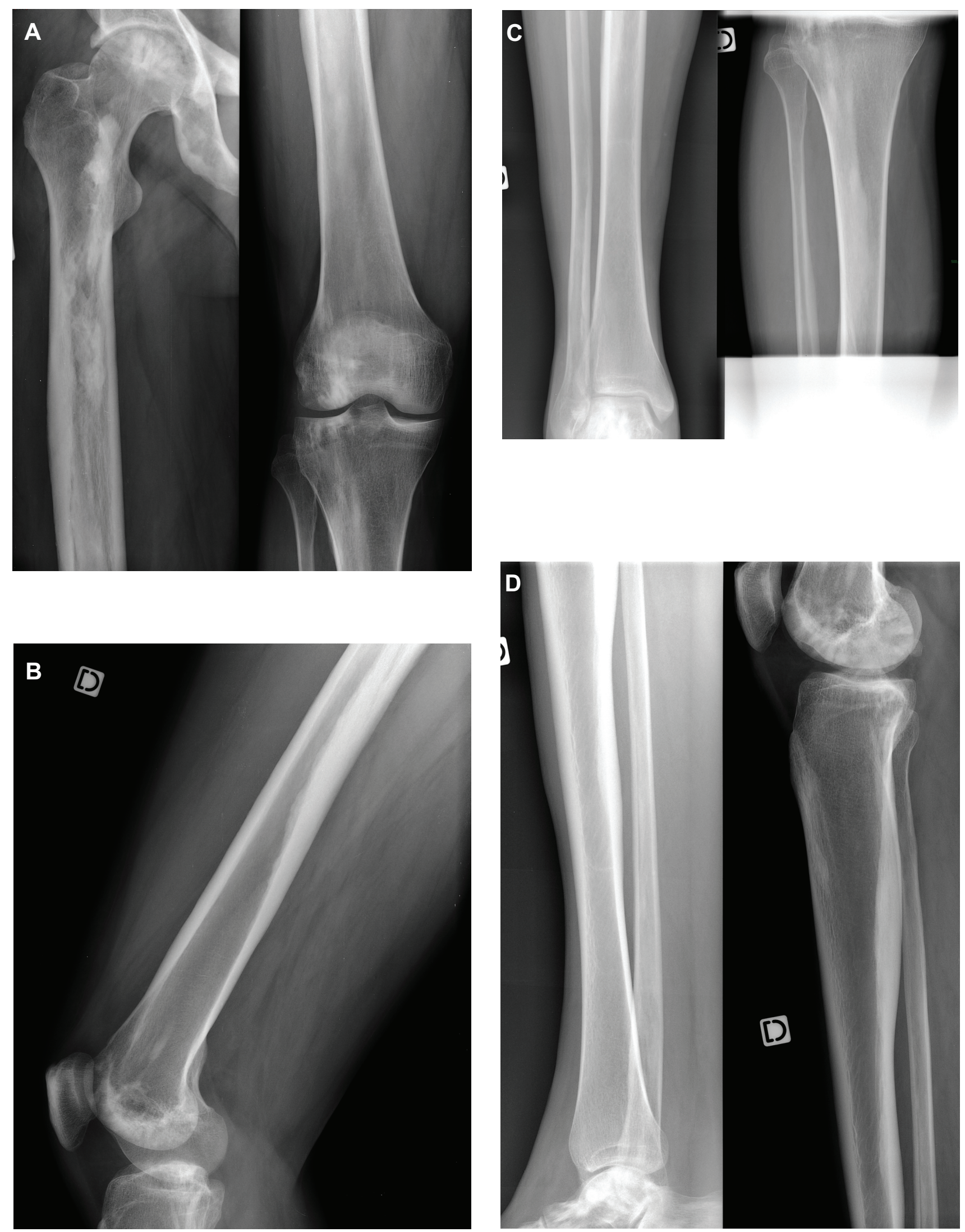

Figure I (A) and (B): anteroposterior and lateral views of the right femur showing dripping cortical hyperostosis. (C) and (D): anteroposterior and lateral views of the right tibia evidencing tibial cortical hyperostosis. (E): lateral view of the right foot showing heterogeneous osseous condensation of the heel. 


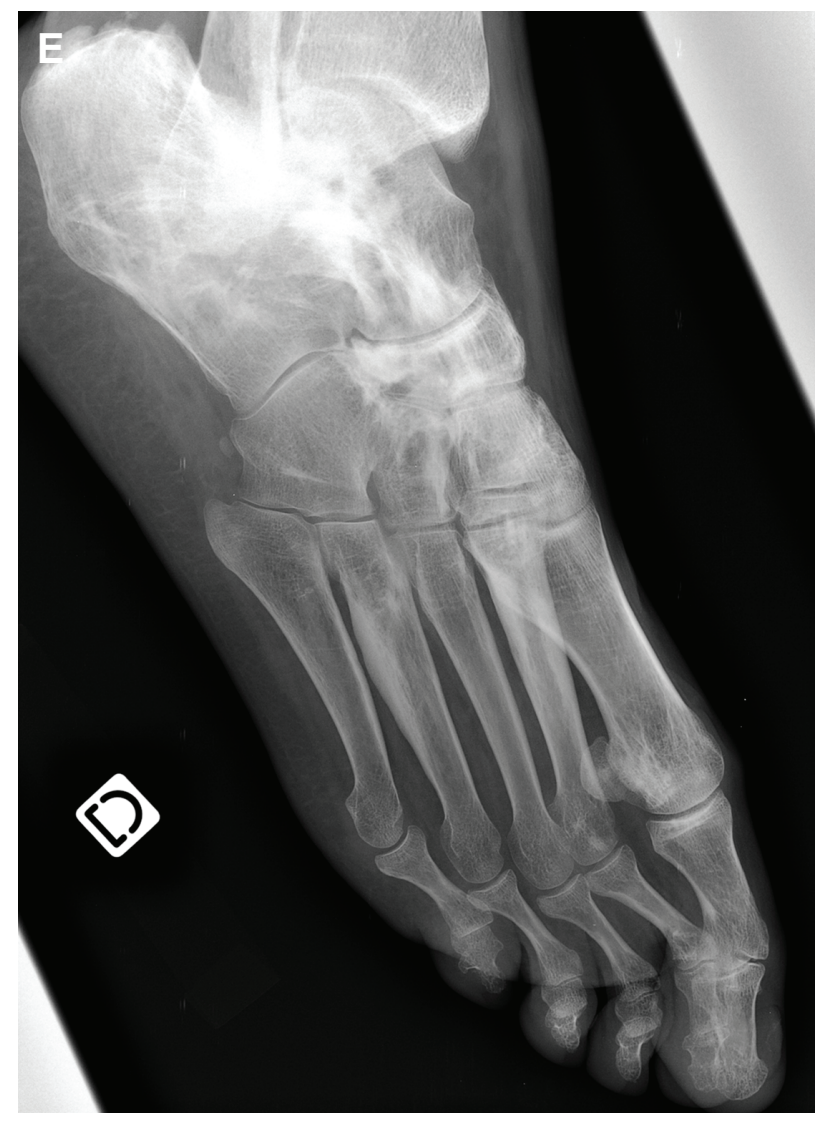

Figure I (Continued)

Over the next 5 years, the evolution of the condition was marked by an increase in pain and its extension to both the lower limbs, with a persistent predilection for the right side.

As there is no curative treatment available, a wide range of analgesic treatments were tested, including the nonsteroidal anti-inflammatory drugs gabapentin and amitriptyline, with unsatisfactory results. Intravenous diphosphonates (pamidronate) were introduced but resulted in little pain relief. The patient became unable to continue his work as a warehouseman.

At this time, because of its refractory state, an association with a peripheral form of inflammatory spondyloarthropathy was suspected. The patient underwent a magnetic resonance imaging (MRI) of his right foot which demonstrated an Achilles tendon enthesopathy. The patient was then referred to our center for a PET combined with CT examination in order to detect other sites of inflammatory enthesopathy. Results are depicted in Figure 3A-E. Lesions of melorheostosis were evidenced again as a strongly increased uptake of nuclides in the same localization as the

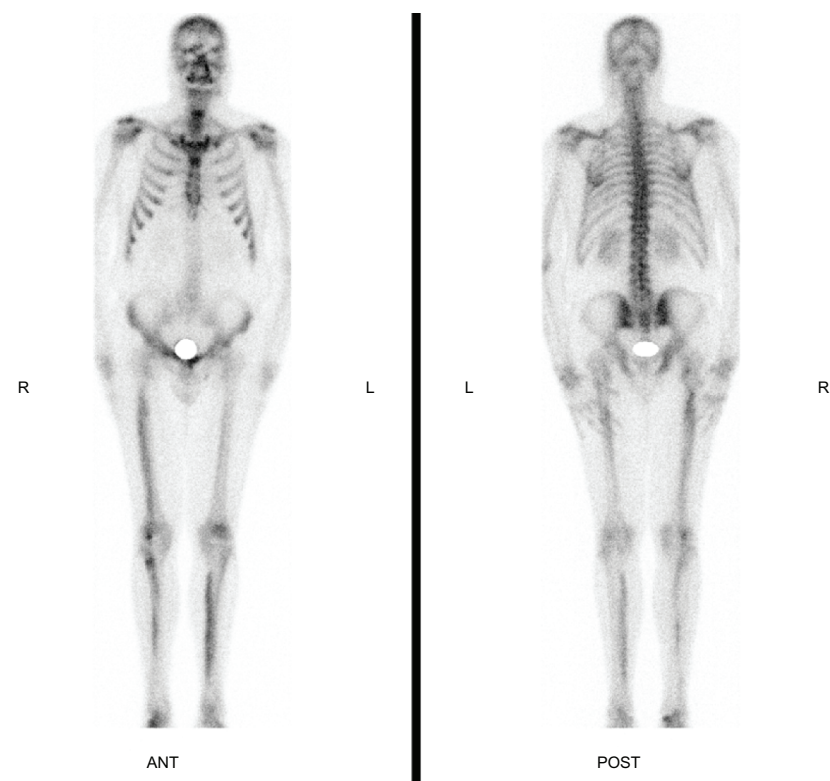

Figure 2 Anterior and posterior whole-body ${ }^{99 \mathrm{~m} T c}$ bone scan showing an increased uptake of nuclides on the lateral cortical of the right femur, the lateral cortical of the right tibia, the right foot and the medial cortical of the left tibia.

HMDP bone scan, consistent with the hyperostosis seen on the CT images. Achilles enthesopathy was confirmed and an increased uptake of nuclides in the tibial tuberosity was shown. Such enthesopathies were compatible with the diagnosis of inflammatory spondyloarthropathy, although the patient was negative for the HLA B27 antigen and methotrexate was thus prescribed to the patient with a relief in the ankle pain.

\section{Discussion}

Melorheostosis, also named Léri's disease after the author who first described it in 1922, is a rare mesenchymal dysplasia, with about 300 cases reported so far in the literature. ${ }^{1}$ It is a benign, sporadic pathology causing abnormalities of the bones and soft tissues. Its incidence is estimated at 0.9 per million, with no sex preference. It usually begins during childhood, with $40 \%$ to $50 \%$ of cases diagnosed before the age of 20 , and flares during the teenage years. There are several hypotheses about its etiology: the most frequent explanation is that a root nerve insult resulted in bone scarring along the corresponding embryonal metamer.

The usual clinical presentation consists of chronic bone pain and joint contractures, with episodes of exacerbation, often associated with soft tissue abnormalities such as edema, cutaneous manifestations (spots of pigmented skin, circumscribed or linear scleroderma), fibrosis, or 

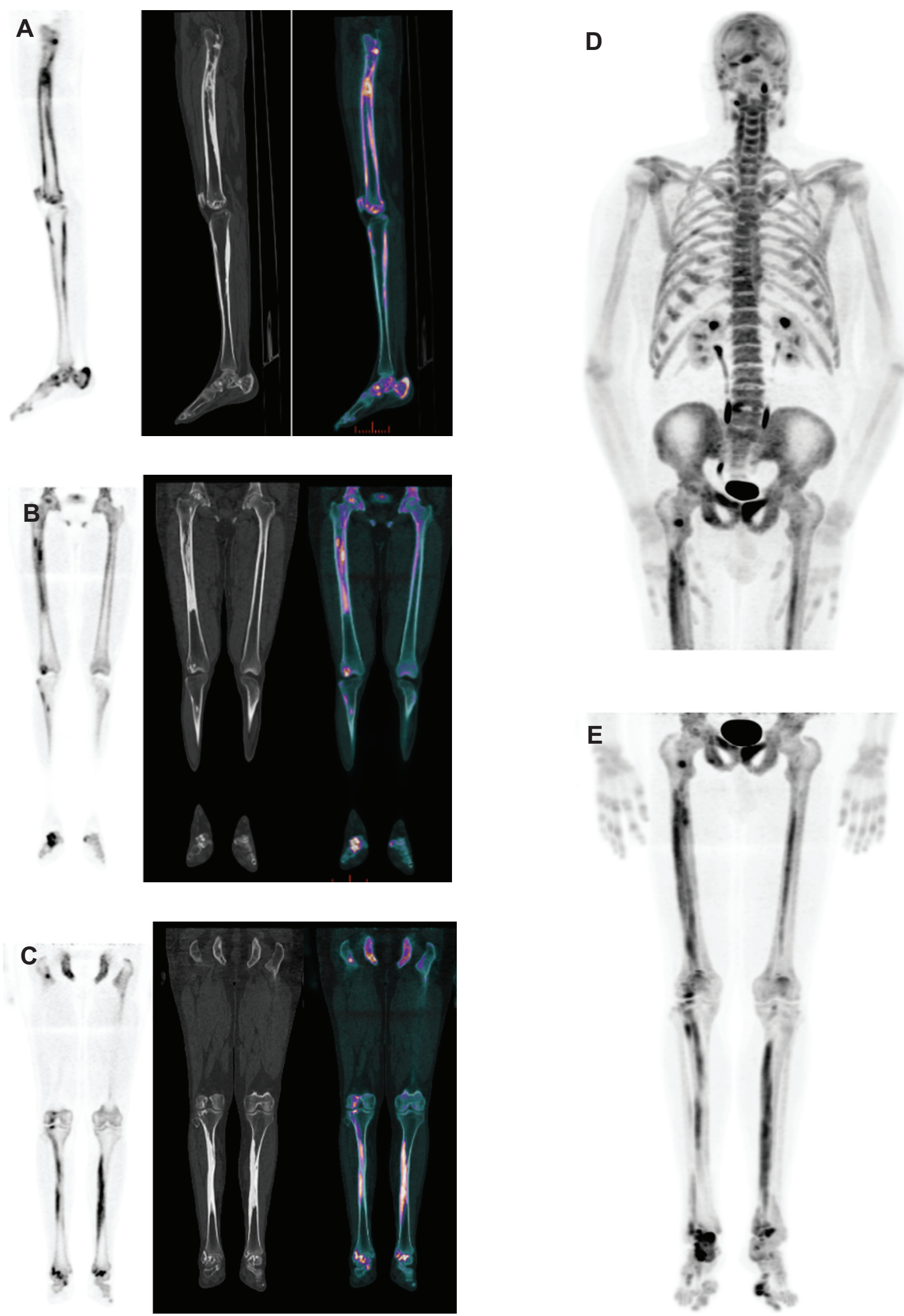

Figure 3 Sagittal plane of the right lower limb (A) and coronal planes of both lower limbs (B and $\mathbf{C})$. The PET images (on the left) evidence increased uptake of nuclides, the CT images in bone window show the cortical thickening of the bones (center). Fusion of both techniques is shown on the right. Maximum Intensity Projection of the whole body PET data (D and E). 
masses composed of adipose, lymphatic, vascular, or osteocartilaginous tissues. ${ }^{2}$ The appendicular skeleton is much more involved than the axial skeleton and the lower extremities more than the upper extremities. ${ }^{2}$ The bony distribution may be monostotic, polyostotic or monomelic, often segmental and unilateral, even through joints. Long bones are more commonly affected, but short bones can be involved too. Craniofacial or spine bones are rarely spanned.

From an imaging point of view, the classic pathognomonic pattern is the so-called "dripping candle wax", figurative description for longitudinal bars of hyperostosis along the cortical bone of long bones. Other patterns are often found according to Freyschmidt, who describes an osteomalike appearance, a myositis ossificans-like appearance, an osteopathia striata-like appearance, and sometimes a mixed situation of all three types of presentation. ${ }^{3} \mathrm{CT}$ and MRI are very helpful in the analysis of the cortical thickening and its extension to the medullary canal of bones.

CT can confirm the presence of calcifications inside the masses and demonstrate their topography. It is often found that they are not directly attached to the bones. ${ }^{4,5}$

MRI appearance of those masses is highly variable due to the presence of calcifications, fat or fibrovascular tissues. Gadolinium enhancement of the surrounding tissues is related to inflammation. ${ }^{4-6}$

The ${ }^{99 \mathrm{~m}} \mathrm{Tc}$ bone scan shows an increased uptake of radionuclide in the angiogram phase, as a function of blood flow. In the bone phase, intense tracer activity is observed in the areas of radiographic abnormalities. The pattern of asymmetrical cortical uptake, sometimes crossing over intermediate joints to involve contiguous bones, is also considered as pathognomonic..$^{7-9}$

The originality of this case report is the whole body ${ }^{18} \mathrm{FNa}$ PET-CT examination that was made of the patient, as there is no report of melorheostosis imaged with ${ }^{18} \mathrm{FNa}$ in the literature to the best of our knowledge. The patient underwent this procedure because of the suspected diagnosis of peripheral form inflammatory spondyloarthropathy. Signs of this pathology are widely searched for with centered MRI studies, which have a high sensitivity in detecting bone edema and enthesitis. Whole-body diffusion (T1 and STIR sequences) MRI has recently been used as a screening tool to detect axial and peripheral signs of spondyloarthropathy. ${ }^{10}$

The ${ }^{18} \mathrm{~F}$ fludeoxyglucose $\left({ }^{18} \mathrm{FDG}\right)$ PET-CT has also been proven valuable in the diagnosis of spondyloarthropathy with enthesitis. ${ }^{11}$
Some centers, like ours, are currently evaluating the use of ${ }^{18} \mathrm{FNa}$ PET-CT in this field, which, at least in this case, was valuable for this diagnosis of spondyloarthropathy. ${ }^{18} \mathrm{FNa}$ is an old bone-scanning agent that was used in nuclear medicine in the $1970 \mathrm{~s} .{ }^{12}$ At this time, it was considered an excellent radiopharmaceutical agent for skeletal imaging, with a fast and high bone uptake along with a rapid blood clearance, allowing a high bone-tobackground-ratio in less than an hour after intravenous injection.

However, its use suffered from two limitations. The first was the high-energy $511 \mathrm{keV}$ annihilation photons produced by the decay of the ${ }^{18} \mathrm{FNa}$, when gamma cameras were mostly optimized for $140 \mathrm{keV}$ photons. With the introduction in the early 1970 s of ${ }^{99 m}$ Tc-labeled bone imaging agents (polyphosphates and, later, pyrophosphates) and the increasing availability of $140 \mathrm{keV}$ optimized gamma cameras, bone scan became one of the most performed examinations in nuclear medicine. In the $1990 \mathrm{~s},{ }^{99 \mathrm{~m}} \mathrm{Tc}$-diphosphonates, with faster blood clearance, became the standard radiopharmaceutical agents for bone scans.

The second reason was the shorter ${ }^{18} \mathrm{FNa}$ half-life of 110 minutes causing difficulties in the efficiency of the production and delivery chains, while ${ }^{99 \mathrm{~m}} \mathrm{Tc}$ is easy to handle. Indeed, ${ }^{99 \mathrm{~m}} \mathrm{Tc}$, whose half-life is about 6 hours, is produced by the decay of ${ }^{99} \mathrm{Mo}$ (Molybdenum), with a half-life of 66 hours. Nuclear Medicine Centers receive a bottle of ${ }^{99} \mathrm{Mo}$ every week, which is enough to have technetium available every day. Those bottles are the so-called "technetium cows" and permit an easy chemical separation of Mo and Tc.

In the early $90 \mathrm{~s},{ }^{18} \mathrm{FNa}$ made a come-back in the development of whole-body PET for research and development techniques, then, in the late $2000 \mathrm{~s}$, in clinical use.

Nowadays, as ${ }^{18}$ FDG PET is becoming a routine examination in oncology, PET cameras with greater spatial resolution and physical sensitivity than conventional gamma cameras have become widely available. PET examination is now always coupled to a CT scan for hybrid imaging, which can go from a 4 detector CT for the older systems to a last-generation $\mathrm{CT}$ for the most recent ones. ${ }^{18} \mathrm{FNa}$ also benefits from the improvements in the production and delivery system driven by the widespread use of ${ }^{18}$ FDG techniques.

Recently, it has been proved that ${ }^{18} \mathrm{FNa}$ PET is superior to classic HMDP bone scans for the assessment of malignant or benignant bone diseases. ${ }^{13-15}$ PET provides a higher spatial resolution, offering both a better sensitivity and specificity 
for the diagnostic. Unlike the HMDP bone scan, whose main drawback is a lesser sensitivity for spine lesions, ${ }^{18} \mathrm{FNa}$ PET sensitivity is not influenced by the anatomical localizations of bone lesions.

The PET examination is coupled with a low-dose CT-scan which allows attenuation correction of the PET emission data and accurate anatomic diagnosis.

The CT images themselves are often under-rated for diagnostic purposes.

In the field of bone diseases, the CT data are valuable and can replace the need for a standard bone CT-scan or for plain radiographs if not yet performed. ${ }^{16}$

Thus, the ${ }^{18} \mathrm{FNa}$ PET-CT is a hybrid technique that brings the best of both imaging worlds to patient care.

In the case of melorheostosis, the PET can replace the HMDP bone scan to assess the topography and extent of the uptake, while the CT part can study hyperostosis, bone deformities, soft-tissue abnormalities and ossifications. Inflammation in the surrounding tissues could be demonstrated with a complementary CT localized acquisition or MRI coupled to a contrast agent.

Regarding the associated diagnosis of spondyloarthropathy, PET is also able to assess enthesitis in the peripheral form with the ${ }^{18} \mathrm{FDG}$ radiotracer and probably even better with the ${ }^{18} \mathrm{FNa}$.

From a practical point of view, the ${ }^{18} \mathrm{FNa}$ PET-CT is a procedure that takes less than 120 minutes, including patient management and imaging acquisition time. After the intravenous administration of the radionuclide, the rapid uptake in bones and fast clearance from the blood allow image recording to start 20 minutes later. Acquisition times can be set to 3 minutes by step on the trunk and upper limbs, then to 1 minute and 30 seconds on the lower limbs. PET steps are about 15 to $20 \mathrm{~cm}$ according to the axial field of view of the PET device. Thus, whole body scan is performed for an average adult patient in no more than 30 to 35 minutes. The CT part of the examination takes no more than 1 minute. It compares favorably with the overall duration of a ${ }^{99 m}$ Tc bone scan of about 4 to 5 hours, including patient management.

The duration is also shorter than a whole-body diffusion (T1 and STIR) MRI examination with a total imaging time for an average patient of 65 minutes $^{10}$.

Concerning the radiation dose, the injected activity for the ${ }^{18} \mathrm{FNa}$ PET can be reduced to 2 to $3 \mathrm{MBq} / \mathrm{kg}$ due to the high sensitivity of new PET detectors. ${ }^{17}$ The effective radiation dose is only slightly higher to that received during a bone scintigraphy ( $4 \mathrm{mSv}$ for an average adult of $70 \mathrm{~kg}$ for the PET-CT versus $3 \mathrm{mSv}$ for the bone scintigraphy). ${ }^{17}$ This slight increase in the radiation dose is well counterbalanced by the numerous advantages of the PET.

In conclusion, we strongly believe that ${ }^{18} \mathrm{FNa} \mathrm{PET}$ imaging will soon become a new standard for bone scanning in the years to come. Its greater sensitivity is an advance in diagnosis. The combination with CT makes it a great tool for the practitioner. Its fast realization, compared to the classic HMDP bone scan or whole body MRI, is very convenient for the patient.

\section{Disclosure}

The authors report no conflict of interest in this work.

\section{References}

1. Leri A, Joanny J. A not yet documented bony disease: hyperostosis of an entire limb or "melorheostosis" [in French]. Bull Mem Soc Med Hop Paris. 1922;46:1141-1146.

2. Jain VK, Arya RK, Bharadwaj M, Kumar S. Melorheostosis: clinicopathological features, diagnosis, and management. Orthopedics. 2009;32:512.

3. Freyschmidt J. Melorheostosis: a review of 23 cases. Eur Radiol. 2001;11: 474-479.

4. Suresh S, Muthukumar T, Saifuddin A. Classical and unusual imaging appearances of melorheostosis. Clin Radiol. 2010;65(8): 593-600.

5. Brown RR, Steiner GC, Lehman WB. Melorheostosis: case report with radiologic-pathologic correlation. Skeletal Radiol. 2000;29: 548-552.

6. Judkiewicz AM, Murphey MD, Resnik CS, Newberg AH, Temple HT, Smith WS. Advanced imaging of melorheostosis with emphasis on MRI. Skeletal Radiol. 2001;30:447-453.

7. Davis DC, Syklawer R, Cole RL. Melorheostosis on three-phase bone scintigraphy. Case report. Clin Nucl Med. 1992;17:561-564.

8. Janousek J, Preston DF, Martin NL, Robinson RG. Bone scan in melorheostosis. J Nucl Med. 1976;17:1106-1108.

9. Drane WE. Detection of melorheostosis on bone scan. Clin Nucl Med. 1987;12:548-551.

10. Althoff CE, Appel H, Rudwaleit M, et al. Whole-body MRI as a new screening tool for detecting axial and peripheral manifestations of spondyloarthritis. Ann Rheum Dis. 2007;66:983-985.

11. Taniguchi Y, Arii K, Kumon Y, et al. Positron emission tomography/ computed tomography: a clinical tool for evaluation of enthesitis in patients with spondyloarthritides. Rheumatology (Oxford). 2010;49: 348-354.

12. Blau M, Ganatra R, Bender MA. 18 F-fluoride for bone imaging. Semin Nucl Med. 1972;2:31-37.

13. Schirrmeister H. Detection of bone metastases in breast cancer by positron emission tomography. Radiol Clin North Am. 2007;45:669-676.

14. Even-Sapir E, Metser U, Mishani E, Lievshitz G, Lerman H, Leibovitch I. The detection of bone metastases in patients with high-risk prostate cancer: $99 \mathrm{mTc}-\mathrm{MDP}$ Planar bone scintigraphy, single- and multi-field-of-view SPECT, 18F-fluoride PET, and 18F-fluoride PET/ CT. J Nucl Med. 2006;47:287-297.

15. Hetzel M, Arslandemir C, Konig HH, et al. F-18 NaF PET for detection of bone metastases in lung cancer: accuracy, cost-effectiveness, and impact on patient management. J Bone Miner Res. 2003;18(12): 2206-2214. 
16. Strobel K, Exner UE, Stumpe KD, et al. The additional value of CT images interpretation in the differential diagnosis of benign vs malignant primary bone lesions with 18F-FDG-PET/CT. Eur J Nucl Med Mol Imaging. 2008;35(11):2000-2008.
17. Grant FD, Fahey FH, Packard AB, Davis RT, Alavi A, Treves ST. Skeletal PET with 18F-fluoride: applying new technology to an old tracer. $J \mathrm{Nucl}$ Med. 2008;49:68-78.

\section{Publish your work in this journal}

Open Access Rheumatology Research and Reviews is an international peer-reviewed, open access journal, publishing all aspects of clinica and experimental rheumatology in the clinic and laboratory including the following topics: Pathology, pathophysiology of rheumatologica diseases; Investigation, treatment and management of rheumatological

Submit your manuscript here: http://www.dovepress.com/open-access-rheumatology-research-and-reviews-journal diseases; Clinical trials and novel pharmacological approaches for the treatment of rheumatological disorders. The manuscript management system is completely online and includes a very quick and fair peerreview system, which is all easy to use. Visit http://www.dovepress.com/ testimonials.php to read real quotes from published authors. 